\title{
Small Intestine Cancer pTO TNM Finding v7
}

National Cancer Institute

\section{Source}

National Cancer Institute. Small Intestine Cancer pTO TNM Finding v7. NCI Thesaurus. Code C89866.

Small intestine cancer with no evidence of primary tumor. (from AJCC 7th Ed.) 